\title{
Penerapan Metode TOPSIS Pemilihan Sosial Media Marketing Untuk Penjualan Aksesoris Pariwisata Lombok
}

\author{
Emi Suryadi*1, Ahmad Yani ${ }^{2}$ \\ ${ }^{1,2}$ Universitas Teknologi Mataram \\ E-mail: *11emisuryadi@gmail.com, ${ }^{2}$ m4dy45@gmail.com
}

\begin{abstract}
Abstrak
Perkembangan teknologi informasi memiliki peran penting dalam kehidupan sehari-hari. Banyak masyakarat yang memanfaatkan teknologi sebagai media marketing dengan tujuan untuk meningkatkan pendapatan melalui internet. Sistem pendukung keputusan diterapkan untuk memilih alternatif sebagai media promosi aksesoris pariwisata. Aksesoris khas lombok cukup terkenal diberbagai masyarakat, banyak karya masyarakatnya yang belum diketahui oleh para wisatawan baik dari dalam maupun dari luar negeri. Fakor ini yang menjadikan masyarakat lombok berantusias untuk memasarkan produknya agar dapat dikenal oleh masyarakat banyak. Metode TOPSIS sebagai metode pengambilan keputusan yang digunakan sebagai solusi untuk meningkatkan penjualan aksesoris. Perhitungan metode ini menunjukkan bahwa satu dari banyaknya data responden yang ada, facebook memiliki nilai paling tinggi dibandingkan dengan sosial media lainnya. Terpilihnya facebook dapat dijadikan sebagai rekomendasi pemasaran yang optimal terhadap alternatif yang ada. Hasil rekomendasi metode ini dapat berubah tergantung dari nilai kriteria terhadap alternatif yang diberikan. Penerapan data responden satu dengan responden lainnya menghasilkan data rekomendasi yang berbeda karena ketersedian data yang dimiliki.
\end{abstract}

Kata kunci-Aksesoris, Lombok, Sosial Media, TOPSIS

\begin{abstract}
The development of information technology has an important role in everyday life. Many people use technology as a marketing medium with the aim of increasing income via the internet. A decision support system is applied to select alternatives as a medium for promoting tourism accessories. Lombok's typical accessories are quite well-known in various communities, many of the people's works are unknown to tourists both from within and from abroad. This factor is what makes the people of Lombok enthusiastic about marketing their products so that they can be recognized by the public. The TOPSIS method is a decision-making method that is used as a solution to increase accessories sales. The calculation of this method shows that one of the many available respondent data, Facebook has the highest value compared to other social media. The selection of Facebook can be used as an optimal marketing recommendation for existing alternatives. The results of the recommendations for this method may change depending on the value of the criteria for the alternatives given. The application of respondent data to other respondents results in different recommendation data due to the availability of the data they have.
\end{abstract}

Keywords-Accessories, Lombok, Social Media, TOPSIS 


\section{PENDAHULUAN}

$\mathrm{T}$ eknologi informasi yang semakin maju menjadikan peran manusia sudah banyak digantikan oleh mesin. Peranan teknologi informasi menjadi hal yang sangat penting dalam kehidupan sehari-hari. Salah satu kemajuan teknologi informasi saat ini ialah dapat dijadikan sebagai pengambilan keputusan. Sistem pendukung keputusan dibuat untuk membantu memilih alternatif yang lebih dari satu. Salah satu metode yang digunakan dalam pengambilan keputusan untuk meningkatkan penjualan aksesoris di pulau Lombok ialah dengan menggunakan metode Technique For Order Preference By Similarity To Ideal Solution (TOPSIS). Metode ini merupakan salah satu metode yang banyak digunakan untuk menyelesaikan pengambilan keputusan secara praktis yang memiliki konsep dimana alternatif yang terpilih merupakan alternatif terbaik yang memiliki jarak terpendek dari solusi ideal positif dan jarak jauh dari solusi ideal negatif [1]. Penelitian terkait yang telah dilakukan Heru Purwanto (2017) bertujuan untuk membantu para konsumen dalam memilih notebook dari banyaknya pilihan yang ditawarkan oleh penjual dengan dua belas kriteria menggunakan metode TOPSIS. Faktor yang menjadi dasar dalam pemilihan Notebook adalah Desain (warna, model, nilai ekstrintik), teknologi pendukung (memori, konektor, performance), Display dan Audio (graphic, sound, pixcel) serta input media (posisi, ukuran) [2]. Satriawaty Mallu (2015) bertujuan untuk menentukan karyawan kontrak untuk menjadi karyawan tetap di PT Gowo motor Group menggunakan TOPSIS. Penentuan karyawan tetap ini dilakukan secara bertahap seperti penyeleksian berkas, tes lisan atau tes tulis, wawancara dan lain sebagainya [3]. Slamet Hidayat, dkk (2016) yang penelitiannya bertujuan memilih guru teladan yang ada di MA-Al Mubarok. Pemilihan guru teladan disekolah tersebut membutuhkan kriteria dan bobot dalam penilaiannya. Penentuan siapa yang menjadi guru teladan digunakan sebuah metode yaitu metode TOPSIS. Didalam penelitiannya mengatakan bahwa metode TOPSIS mampu memilih alternatif terbaik dari sejumlah alternatif yang ada [4]. Sistem pengambilan keputusan merupakan langkah yang perlu diambil karena melihat begitu sulit untuk menentukan keputusan. Hasil pengambilan keputusan diharapkan dapat memberikan rekomendasi sehingga menghasilkan solusi yang sesuai dengan harapan yang diinginkan oleh para pengguna atau penggiat usaha.

Sosial media merupakan sarana komunikasi modern yang saat ini sudah banyak dimanfaatkan oleh masyarakat. Seiring kemajuan teknologi manfaat sosial media tidak hanya digunakan sebagai media komunikasi, namun dapat dijadikan sebagai sarana promosi dalam meningkatkan omzet (pendapatan) di dunia internet. Adanya sosial media lokasi jarak yang ada antara penjual dan konsumen tidak lagi menjadi hambatan dan kendala untuk mempromosikan produknya. Kemajuan teknologi ini terus berkembang membuat para pengguna sosial media banyak yang berpikir tentang alternatif yang akan digunakan dalam memasarkan produk ke tengah-tengah masyarakat. Kriteria pemilihan sosial media ini menggunakan jumlah pengguna, jumlah followers, fleksibel dan atraktif, fitur dan fasilitas memadai. Kriteria ini dijadikan sebagai pertimbangan dalam pemilihan sosial media.

Aksesoris khas Lombok cukup terkenal di berbagai masyarakat, banyak karya-karya masyarakatnya yang belum diketahui oleh para wisatawan baik dari dalam maupun dari luar negeri. Hal ini yang menjadikan masyarakat Lombok berantusias untuk memasarkan produknya agar dapat dikenal oleh masyarakat banyak. Masyarakat Lombok memulai mempromosikan produknya melalui sosial media, faktor ini terlihat karena banyaknya pengguna sosial media menjadikannya sebagai salah satu alternatif pilihan untuk media pemasaran. Problem yang terjadi saat ini adalah banyaknya sosial media membuat para pembisnis kebingungan untuk menentukan jenis sosial media mana yang optimal untuk digunakan. Metode TOPSIS sebagai salah metode sistem pendukung keputusan yang akan digunakan untuk mengambil keputusan

Suryadi, et al., [Penerapan Metode TOPSIS Pemilihan Sosial Media Marketing Untuk Penjualan Aksesoris Pariwisata Lombok] 
atas dasar kriteria-kriteria yang telah ditetapkan. Hasil yang diperoleh dapat dijadikan sebagai rekemendasi terhadap alternatif yang lain.

\section{METODE PENELITIAN}

Data yang diperoleh melalui studi pustaka maupun lapangan diolah agar mendapatkan hasil penelitian. Analisis data merupakan salah satu proses penelitian yang dilakukan setelah semua data yang diperlukan guna memecahkan permasalahan yang diteliti sudah diperoleh secara lengkap [5]. Ketajaman dan ketepatan dalam penggunaan alat analisis sangat menentukan keakuratan pengambilan keputusan, untuk itu kegiatan analisis data tidak dapat diabaikan begitu saja dalam proses penelitian. Metode yang digunakan dalam penelitian ini adalah metode Action Research. Metode ini dimulai dari melakukan perencanaan, tindakan, observasi dan refleksi [6]. Tahapan metode Action Research dalam penelitian ini dapat dilihat pada Gambar 1 di bawah ini.

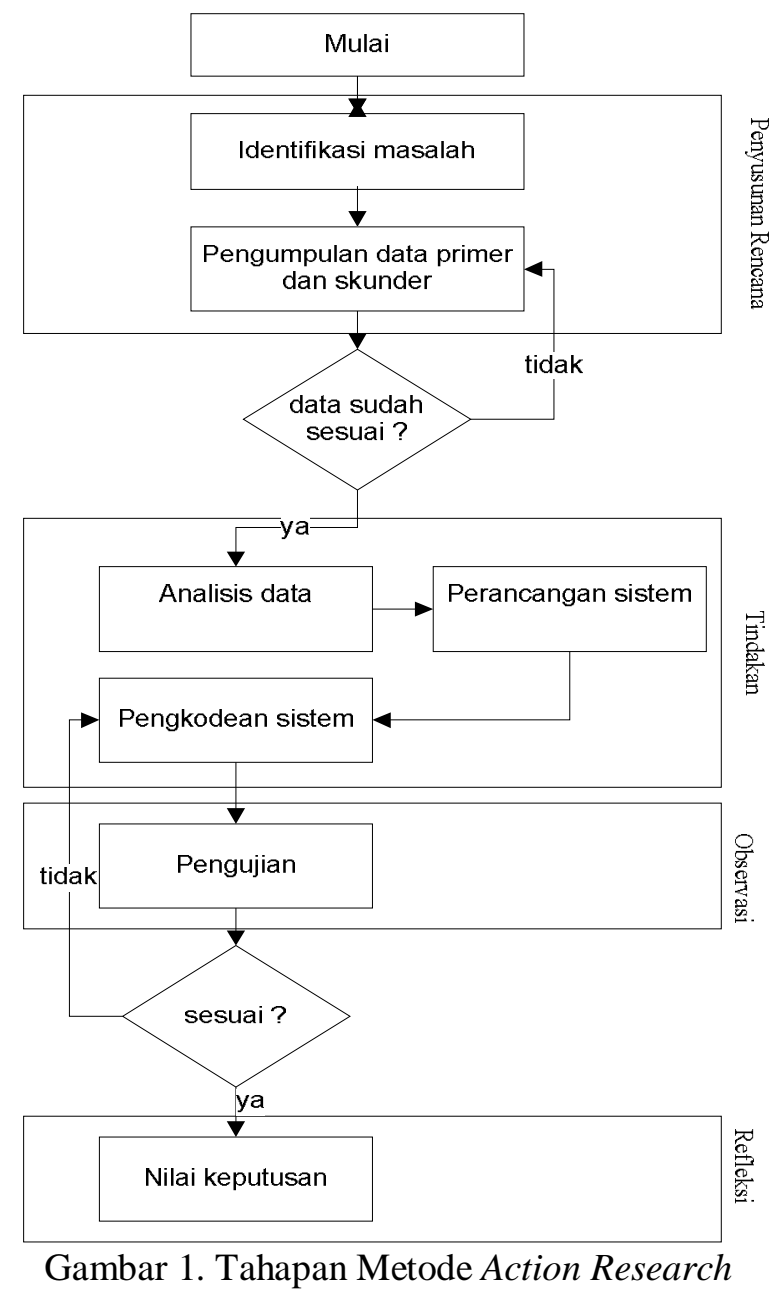

Pada Gambar 1 di atas merupakan tahapan metode action research yang mana setiap langkahnya terbagi menjadi 4 bagian. Tahap penyusunan rencana ini termasuk pada langkah identifikasi masalah dan pegumpulan data, sedangkan pada tahap tindakan ialah analisis data, perancangan sistem dan pengkodean. Untuk tahap observasi ini merupakan proses pengujian

Suryadi, et al., [Penerapan Metode TOPSIS Pemilihan Sosial Media Marketing Untuk Penjualan Aksesoris Pariwisata Lombok] 
sistem / aplikasi yang dibuat dan untuk tahap terakhir yaitu refleksi mengambil keputusan dari rekomendasi sistem yang diberikan.

\subsection{Data Responden}

Berdasarkan data bahwa jumlah pengguna sosial media yang aktif sebanyak 160 juta jiwa yang ada di Indonesia [7], persentase jumlah pengguna sosial media sebagai berikut.

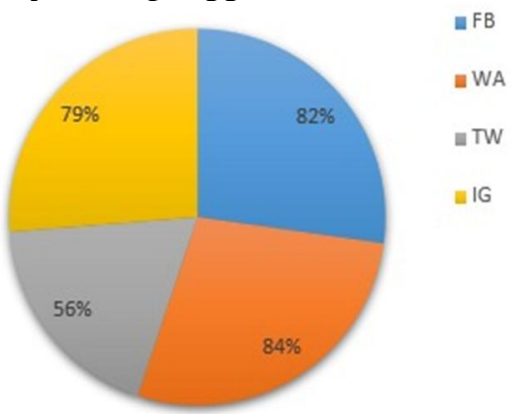

Gambar 2. Jumlah Pengguna

Bedasarkan Gambar 2 data responden yang aktif menggunakan sosial media yaitu $82 \%$ untuk pengguna Facebook, untuk 84\% jumlah pengguna WhatsApp, sedangkan 56\% untuk pengguna Twitter dan $79 \%$ jumlah pengguna Instagram. Sedangkan tanggapan responden terhadap jumlah followers sosial media yang dimiliki.

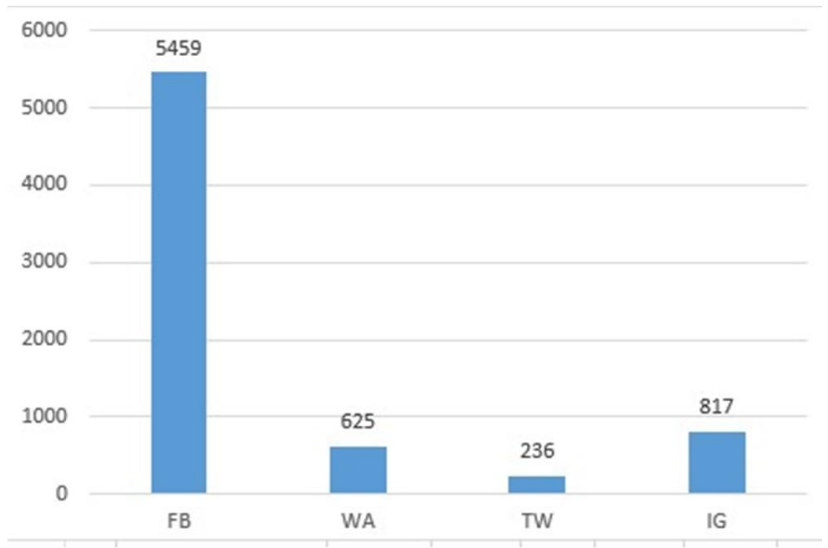

Gambar 3. Jumlah Followers

Grafik Gambar 3 di atas menunjukkan bahwa jumlah followers yang dimiliki Facebook sebanyak 5459, followers WhatsApp sebanyak 625, sedangkan followers Twitter 236 dan untuk followers Instagram sebanyak 817 . Tangapan responden terhadap kriteria yaitu tentang fleksibel dan atraktif terhadap sosial media yang dimiliki. 


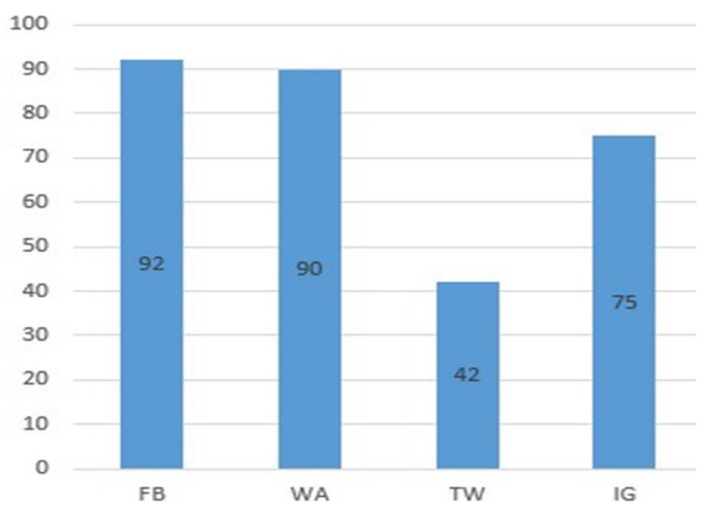

Gambar 4. Fleksibel dan Atraktif

Grafik di atas menunjukkan bahwa penilaian responden terhadap sosial media mengenai tingkat fleksibel dan atraktif yang dimiliki yaitu untuk Facebook 92, WhatsApp 90, sedangkan Twitter 42 dan Instagram 75. Sedangkan untuk penilaian kriteria berikutnya yaitu fitur dan fasilitas, kriteria ini merupakan hasil penilaian responden yang didapatkan sebagai berikut.

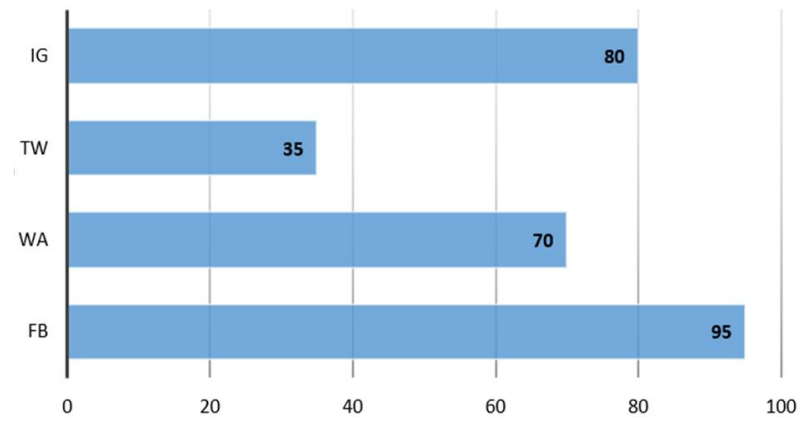

Gambar 5. Fitur Dan Fasilitas Memadai

Grafik di atas adalah hasil penilaian responden tentang Fitur dan Fasilitas yang tersedia di sosial media yaitu Facebook 95, WhatsApp 70, Twitter 35 dan untuk Instagram 80.

\section{2 Relasi Antar Tabel Basis Data}

Pada relasi antar tabel ini akan memperlihatkan rancangan fisik basis data dan juga akan menghasilkan tabel-tabel yang nantinya akan digunakan dalam proses implementasi sistem [8]. Hasil implementasi relasi antara tabel satu dengan tabel lainnya dapat dilihat pada Gambar 6 di bawah ini. 


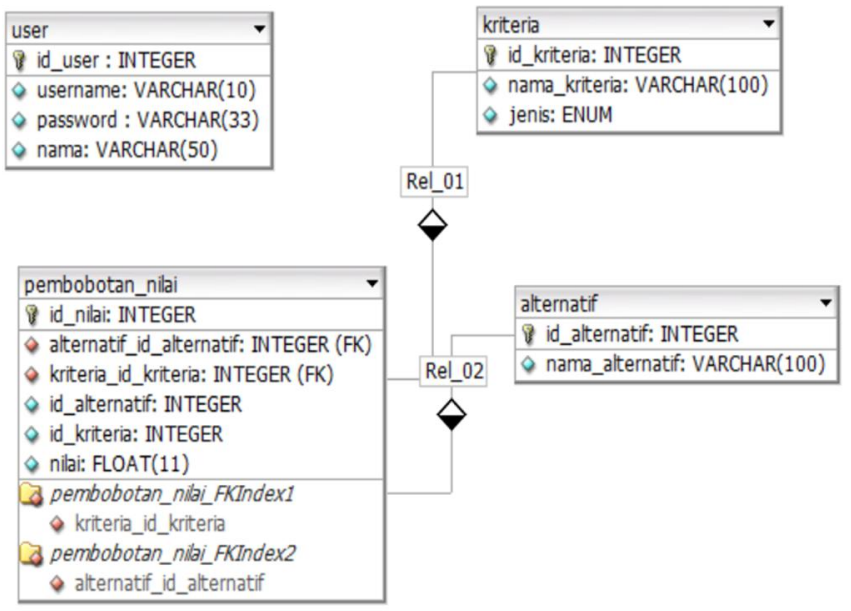

Gambar 6. Relasi Tabel

Gambar 6 di atas memiliki relasi dengan tabel lainnya. Dimana tabel kriteria berelasi dengan tabel pembobotan_nilai sedangkan pada tabel alternatif juga berelasi dengan tabel pembobotan_nilai.

\section{3 Use Case Diagram}

Use case diagram merupakan pemodelan untuk kelakuan sistem informasi yang akan dibuat [9]. Gambaran interaksi dari seorang aktor terhadap sistem yang dibangun dapat dilihat sebagai berikut.

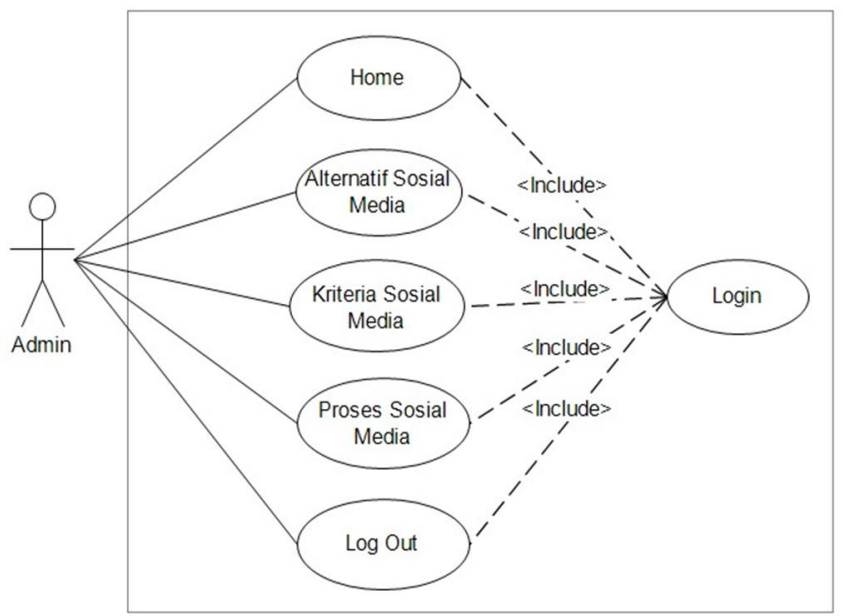

Gambar 7. Use Case Diagram

Admin pertama melakukan proses login ke sistem dengan menggunakan username dan password yang benar. Setelah berhasil login admin akan di bawa ke menu utama, dimana admin bisa melakukan penginputan data alternatif, data kriteria serta melakukan proses perhitungan dari nilai kriteria yang diinputkan. Setelah proses berhasil, admin bisa mengembalikan sistem ke tahap awal dan dapat melakukan proses log out. 


\section{4 Technique for Order Preference by Similarity to Ideal Solution (TOPSIS)}

TOPSIS adalah salah satu metode pengambilan keputusan yang didasarkan pada konsep dimana alternatif terpilih yang terbaik tidak hanya memiliki jarak terdekat dari solusi ideal posistif, namun juga memiliki jarak terpanjang dari solusi ideal negatif (Hwang, 1981) (Zeleny, 1982). Konsep ini banyak digunakan pada beberapa model MADM (Multi-Attribute Decision Making) untuk menyelesaikan masalah keputusan secara praktis (Hwang,1993) (Liang, 1999)(Yeh, 2000).

TOPSIS membutuhkann rating kinerja setiap alternatif Ai pada setiap kriteria $\mathrm{Ci}$ yang ternormalisasi, yaitu:

$$
r_{i j}=\frac{x_{i j}}{\sqrt{\sum_{i=1}^{m} x_{i j}^{2}}} \quad \text { Dengan } i=1,2 \ldots ., m ; \text { dan } j=1,2 \ldots ., n .
$$

Solusi ideal positif A+ dan solusi ideal negatif A- dapat ditentukan berdasarkan rating bobot ternormalisasi (yij) sebagai:

$$
\begin{aligned}
& \mathrm{y}_{\mathrm{ij}}=\mathrm{w}_{\mathrm{i}} \mathrm{r}_{\mathrm{ij}} \\
& \mathrm{A}^{+}=\left(\mathrm{y}_{1}^{+}, \mathrm{y}_{2}^{+}, \ldots, \mathrm{y}_{\mathrm{n}}^{+}\right) \\
& \mathrm{A}^{-}=\left(\mathrm{y}_{1}^{-}, \mathrm{y}_{2}^{-}, \ldots, \mathrm{y}_{\mathrm{n}}^{-}\right)
\end{aligned}
$$

dengan

$$
\begin{aligned}
& y_{j}^{+}=\left\{\begin{array}{cc}
\max y_{i j} & \text { Jika } j \text { adalah atribut keuntungan } \\
\mathrm{i} & \\
\min y_{i j} & \text { Jika } j \text { adalah atribut biaya } \\
\mathrm{i} & \text { Jika } \mathrm{j} \text { adalah atribut keuntungan }
\end{array}\right. \\
& \mathrm{y}_{\mathrm{j}}^{-}=\left\{\begin{array}{cc}
\min \mathrm{y}_{\mathrm{ij}} & \\
\mathrm{i} & \text { Jika } \mathrm{j} \text { adalah atribut biaya } \\
\max \mathrm{y}_{\mathrm{ij}} & \\
\mathrm{i} &
\end{array}\right.
\end{aligned}
$$

Jarak antara alternatif $A_{i}$ dengan solusi ideal positif dirumuskan sebagai :

$$
\mathrm{D}_{\mathrm{i}}^{+}=\sqrt{\sum_{\mathrm{j}=1}^{\mathrm{n}}\left(\mathrm{y}_{\mathrm{i}}^{+}-\mathrm{y}_{\mathrm{ij}}\right)^{2}} \quad \mathrm{i}=1,2, \ldots, \mathrm{m} .
$$

Jarak antara alternatif $A_{i}$ dengan solusi ideal negatif dirumuskan sebagai :

$$
D_{i}^{-}=\sqrt{\sum_{j=1}^{n}\left(y_{i j}-y_{i}^{-}\right)^{2}} \quad i=1,2, \ldots ., m .
$$

Nilai preferensi untuk setiap alternatif $\left(\mathrm{V}_{\mathrm{i}}\right)$ diberikan sebagai :

$$
V_{i}=\frac{D_{i}^{-}}{D_{i}^{-}-D_{i}^{+}} \quad i=1,2, \ldots, m .
$$

Nilai $V_{i}$ yang lebih besar menunjukkan bahwa alternatif $A_{i}$ lebih dipilih [10].

Kriteria pemilihan sosial media marketing ini, menggunakan empat kriteria seperti yang terdapat pada tabel di bawah ini.

Tabel 1. Kriteria Pemilihan Sosial Media Marketing

\begin{tabular}{|c|l|l|}
\hline No. & \multicolumn{1}{|c|}{ Kriteria } & \multicolumn{1}{c|}{ Keterangan } \\
\hline 1 & Jumlah pengguna & Jumlah penguna sosial media di indonesia \\
\hline 2 & Jumlah followers & Jumlah followers yang dimiliki pada setiap sosial media \\
\hline 3 & Fleksibel dan atraktif & Kemudahan dalam menggunakan sosial media \\
\hline 4 & Fitur dan fasilitas memadai & Fasilitas yang disediakan pada sosial media \\
\hline
\end{tabular}

Tabel di atas mejelaskan mengenai kriteria yang digunakan pada pemilihan sosial media yang meliputi jumlah pengguna, jumlah followers, fleksibel dan atraktif dan fitur dan fasilitas 
memadai. Nilai Optimal adalah nilai yang diperoleh melalui suatu proses dan dianggap sebagai solusi jawaban yang paling baik dari semua solusi yang ada [11].

\section{HASIL DAN PEMBAHASAN}

Halaman pertama sistem akan menampilkan menu login, yang mana menu login ini pengguna memasukkan username dan password untuk masuk ke menu utama. Tampilan halaman area login sistem ini dapat dilihat pada Gambar 8 berikut.

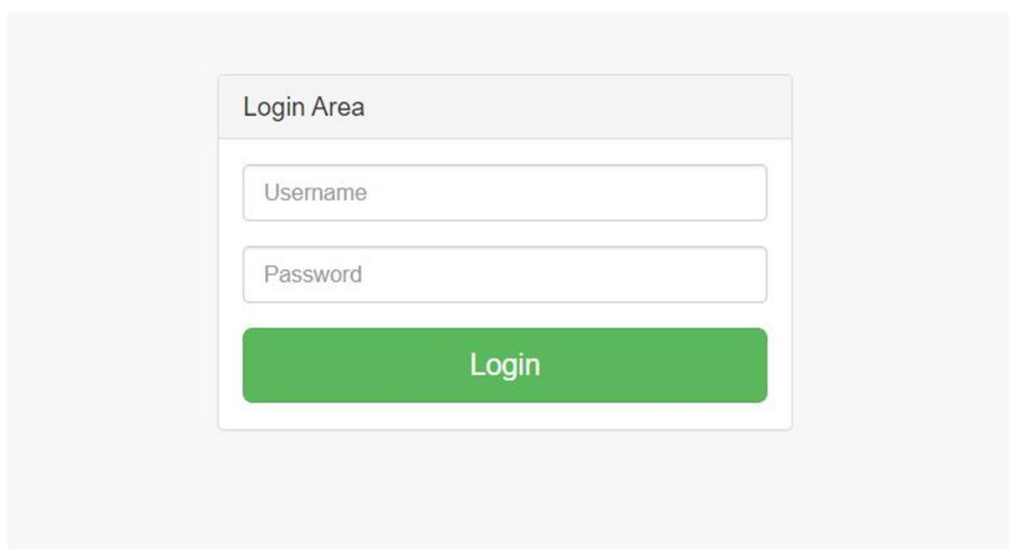

Gambar 8. Halaman Login

Jika pengguna salah memasukkan username dan password maka pengguna tidak bisa masuk ke menu utama, namun jika berhasil maka pengguna akan diarahkan ke menu utama sistem. Tampilan menu utama dapat dilihat pada Gambar 9 di bawah ini.

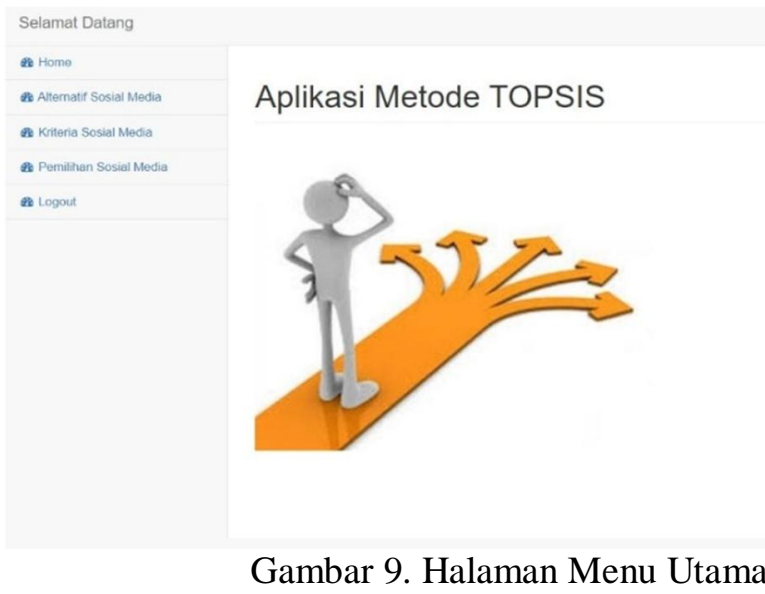

Pada halaman menu utama menampilkan seluruh menu-menu yang terdapat pada sistem diantaranya data alternatif, data kriteria, bobot kriteria, nilai keputusan dan logout, dari masingmasing menu tersebut digunakan untuk menginputkan semua data-data yang dibutuhkan oleh sistem. Adapun tampilan dan penjelasan dari masing-masing halaman menu yang terdapat pada menu utama sebagai berikut. 


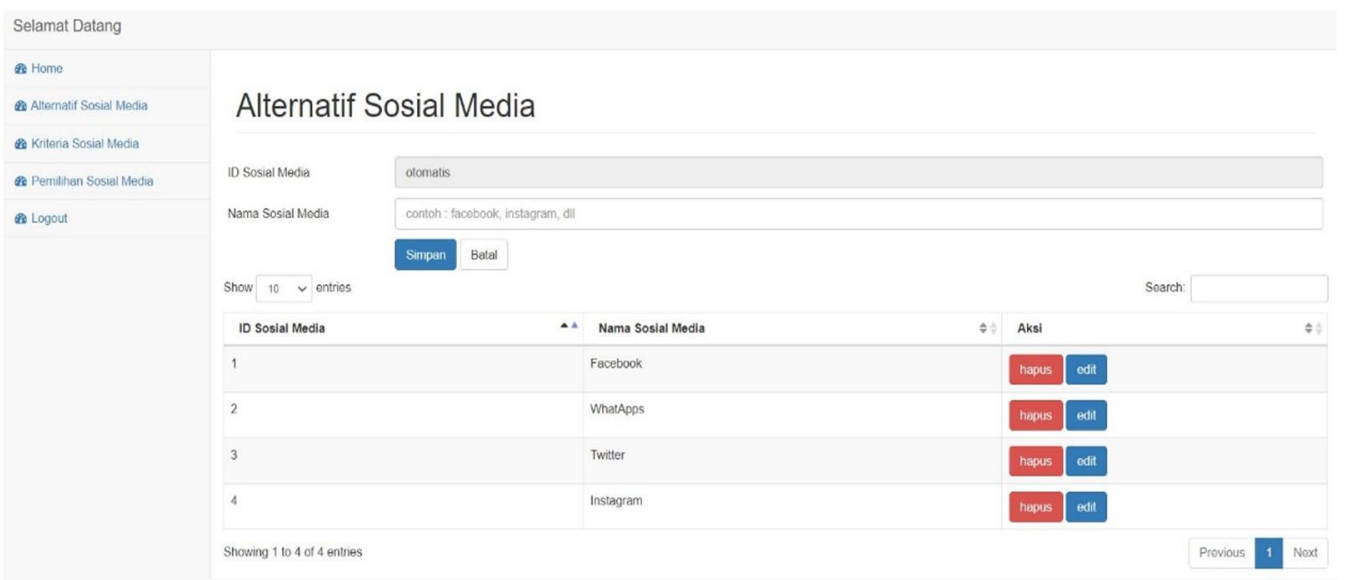

Gambar 10. Halaman Menu Entry Data Alternatif

Pada halaman ini digunakan untuk memasukkan data sosial media yang akan dijadikan sebagai alternatif. Sedangkan untuk halaman bobot kriteria sebagai penentu alternatif terbaik formnya dapat dilihat sebagai berikut.

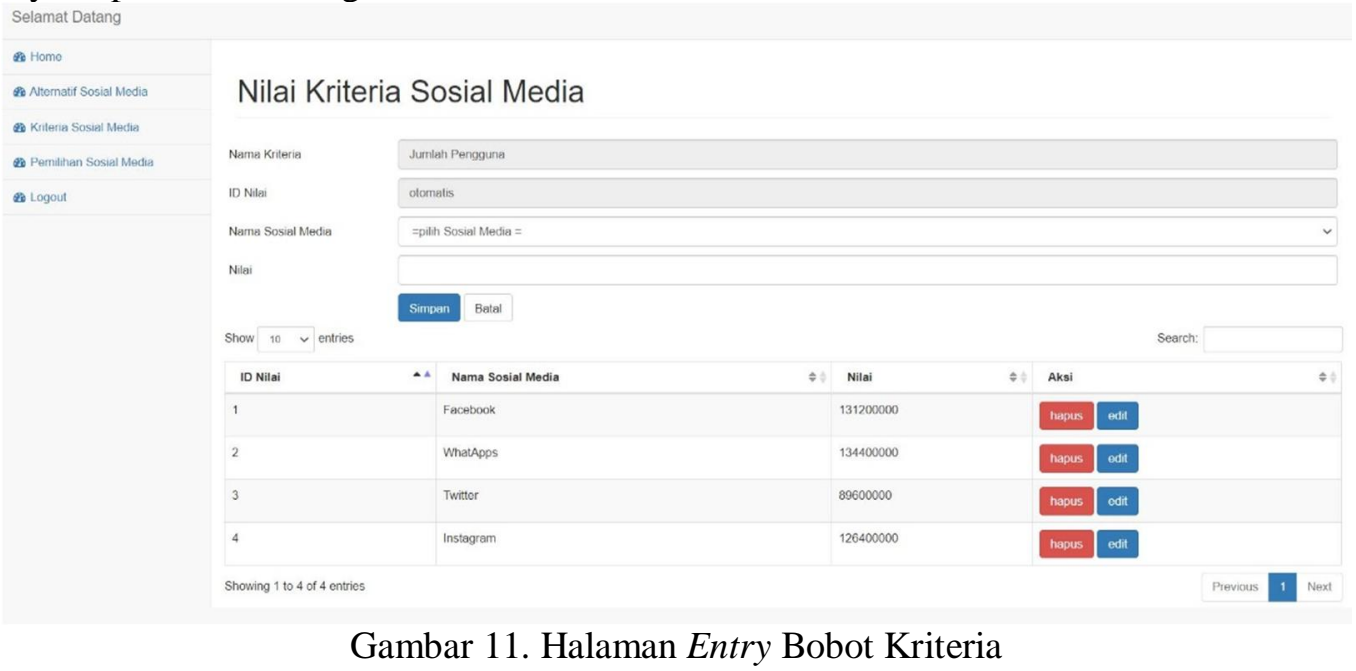

Halaman ini untuk menginputkan bobot kriteria yang akan digunakan dalam pemilihan alternatif (sosial media marketing). Setelah semua alternatif diberikan bobot, maka langkah selanjutnya adalah tahap untuk menentukan nilai kriteria yang ada pada menu pemilihan sosial media. 

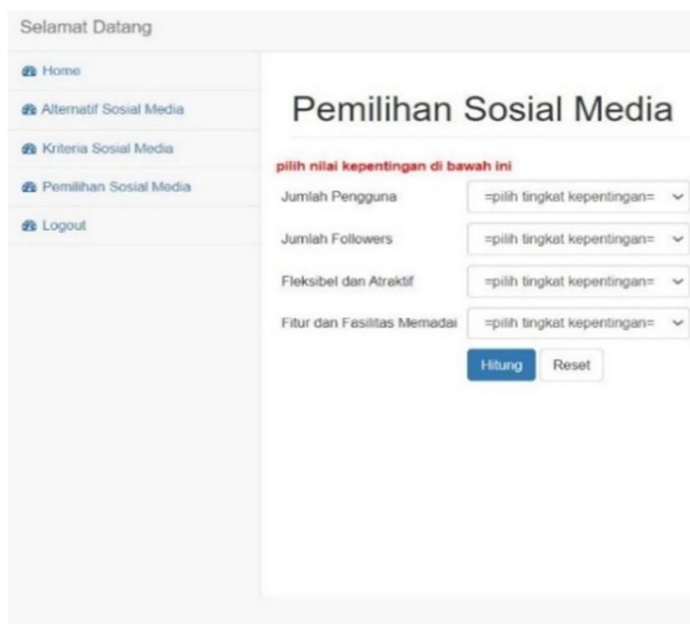

Gambar 12. Halaman Penentuan Bobot Kriteria

Menu pemilihan sosial media ini digunakan untuk menentukan nilai keputusan terhadap sosial media yang akan dijadikan sebagai pilihan. Pada Gambar 13 merupakan hasil perhitungan metode dari bobot yang diberikan.

\begin{tabular}{|c|c|c|c|c|}
\hline jenis & benefit & benefit & benefit & benefit \\
\hline kepentingan & 5 & 4 & 3 & 3 \\
\hline Alternatif / Kriteria & Jumlah Pengguna & Jumlah Followers & Fleksibel dan Atraktif & Fitur dan Fasilitas Memadai \\
\hline Facebook & 131200000 & 5459 & 92 & 95 \\
\hline WhatApps & 134400000 & 625 & 90 & 70 \\
\hline Twitter & 89600000 & 236 & 42 & 35 \\
\hline Instagram & 126400000 & 817 & 75 & 80 \\
\hline \multicolumn{5}{|l|}{ pembagi } \\
\hline 243478787.57707 & \multicolumn{2}{|c|}{5560.0801253219} & 154.76756766196 & 146.79918255903 \\
\hline \multicolumn{5}{|l|}{ ternormalisasi } \\
\hline 0.53885597716996 & \multicolumn{2}{|c|}{0.98182038333196} & 0.59443978728763 & 0.64714256812566 \\
\hline 0.55199880588143 & \multicolumn{2}{|c|}{0.11240845202097} & 0.58151718321616 & 0.47684189230312 \\
\hline 0.36799920392095 & \multicolumn{2}{|c|}{0.042445431483118} & 0.27137468550087 & 0.23842094615156 \\
\hline 0.51914173410277 & \multicolumn{2}{|c|}{0.14694032848181} & 0.46459765268013 & 0.54496216263214 \\
\hline \multicolumn{5}{|l|}{ terbobot } \\
\hline 2.6942798858498 & \multicolumn{2}{|c|}{3.9272815333278} & 1.7833193618629 & 1.941427704377 \\
\hline 2.7599940294071 & \multicolumn{2}{|c|}{0.44963380808388} & 1.7445515496485 & 1.4305256769094 \\
\hline 1.8399960196048 & \multicolumn{2}{|c|}{0.16978172593247} & 0.81412405650262 & 0.71526283845468 \\
\hline 2.5957086705138 & \multicolumn{2}{|c|}{0.58776131392725} & 1.4537929580404 & 1.6348864878964 \\
\hline
\end{tabular}




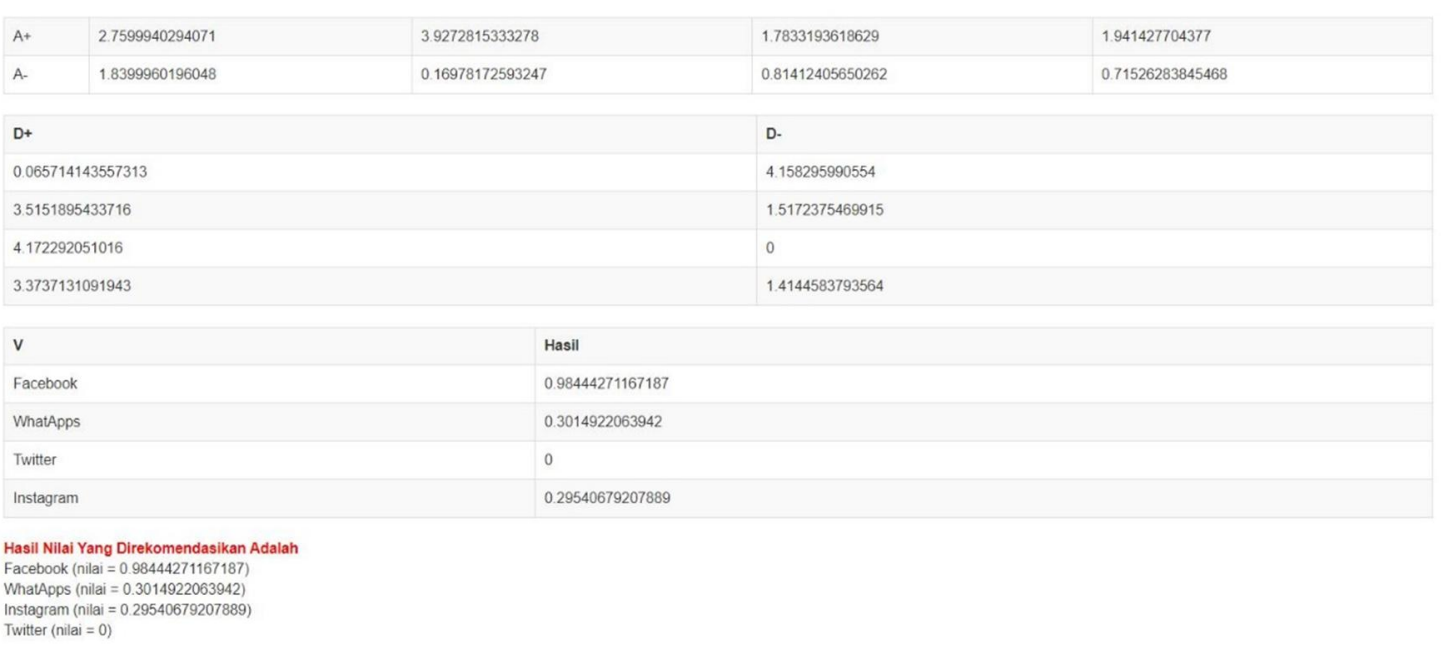

Gambar 13. Hasil Perhitungan Metode

Hasil perhitungan metode TOPSIS dapat menampilkan urutan nilai tertinggi sampai terendah. Sosial media yang memiliki nilai tertinggi merupakan alternatif terpilih untuk dijadikan sebagai rekomendasi. Dalam hal ini sosial media yang memiliki nilai tertinggi berdasarkan hasil perhitungan adalah Facebook dengan nilai (0.98444271167187) disusul oleh WhatApps (0.3014922063942), Instagram (0.29540679207889) dan Twitter (0).

\section{KESIMPULAN}

Berdasarkan implementasi metode TOPSIS pemilihan sosial media marketing dapat ditarik kesimpulan bahwa sosial media yang optimal dapat dijadikan sebagai media promosi untuk meningkatkan penjualan aksesoris pariwisata di pulau Lombok adalah facebook. Facebook memiliki nilai perhitungan yang lebih tinggi dibandingkan dengan nilai sosial media lainnya seperti WhatApps, Instagram, dan Twitter yaitu dengan nilai 0.98444271167187. Hasil perhitungan nilai ini diperoleh dari salah satu data responden yang ada di pulau Lombok. Nilai perhitungan dapat berubah tergantung data responden yang dimiliki. Namun hal ini dapat dijadikan sebagai rekomendasi pengambilan keputusan terhadap alternatif yang ada.

\section{SARAN}

Untuk pengembangan penelitian selanjutnya dapat dilakukan perbandingan metode yaitu dengan menggunakan metode Analytical Hierarchy Process (AHP) dan metode Simple Additive Weighting (SAW). Penelitian ini memiliki empat kriteria untuk kedepannya penelitian ini bisa tambahkan data kriterianya sehingga hasil yang didapatkan lebih optimal didalam melakukan keputusan.

\section{UCAPAN TERIMA KASIH}

Penulis mengucapkan terima kasih kepada Kampus Univeristas Teknologi Mataram yang telah memberi kesempatan dan dukungan kepada peneliti untuk melaksanakan proses penelitian sesuai dengan jadwal dan pembiayaan yang telah diberikan oleh pemerintah, sehingga proses

Suryadi, et al., [Penerapan Metode TOPSIS Pemilihan Sosial Media Marketing Untuk Penjualan Aksesoris Pariwisata Lombok] 
penelitian dosen pemula ini dapat terlaksana dengan baik dan lancar sesuai dengan jadwal yang telah ditetapkan.

\section{DAFTAR PUSTAKA}

[1] F. Riandari, P. M. Hasugian, and I. Taufik. 2017, "Sistem Pendukung Keputusan Menggunakan Metode TOPSIS Dalam Memilih Kepala Departemen pada Kantor Balai Wilayah Sungai Sumatera II Medan,” J. Inform. Pelita Nusant., Vol. 2, No. 1, pp. 6-13.

[2] Heru Purwanto. 2017, "Sistem Penunjang Keputusan Pemilihan Notebook Dengan Menggunakan Metode TOPSIS," Jurnal Ilmu Pengetahuan dan Teknologi Komputer Vol. 2. No. 2.

[3] S. Mallu, 2015, "Sistem Pendukung Keputusan Penentuan Karyawan Kontrak Menjadi Karyawan Tetap Menggunakan Metode Topsis," J. Ilm. Teknol. dan Inf. Terap., Vol. 1, No. 2, pp. 36-42.

[4] S. Hidayat, R. Irviani, and Kasmi, 2016, "Sistem Pendukung Keputusan Pemilihan Guru Teladan Ma Al Mubarok Batu Raja Menggunakan Metode Topsis," J. TAM (Technology Accept. Model., Vol. 6, No. pp. 1-8, 2, [Online]. Available: www.stmikpringsewu.ac.id.

[5] A. Muhson, 2006, “Teknik Analisis Kuantitatif," Makal. Tek. Anal. II, pp. 1-7, [Online]. Available: http://staffnew.uny.ac.id

[6] Nafiah and S. Hartatik, 2020, "Penerapan Manajemen Pembelajaran Berbasis Daring Dengan Menggunakan Aplikasi Google Classroom Untuk Meningkatkan Kemampuan Mahasiswa Dalam Membuat Perangkat Pembelajaran," Education And Human Development Journal, 5(1), 9-23. Https://Doi.Org/10.33086/Ehdj.V5i1.1486

[7] We Are Social \& Hootsuite, 2020, "Indonesia Digital Report 2020," Glob. Digit. Insights, p. 247, doi: https://datareportal.com.

[8] R. Andriani, A. Pujianto, S. Megira, and A. R. Pangesti, "Perancangan Basis Data pada Website E-Kartu Nikah," pp. 47-57.

[9] D. Wira, T. Putra, and R. Andriani, 2019, "Unified Modelling Language ( UML ) Dalam Perancangan Sistem Informasi Permohonan Pembayaran Restitusi SPPD,” Vol. 7, No. 1.

[10] S. Kusumadewi, S. Hartati, A. Harjoko, and R. Wardoyo, Eds., 2006, Fuzzy MultiAttribute Decision Making (Fuzzy MADM)., Pertama. Graha Ilmu, Yogyakarta.

[11] E. Suryadi, E. Wahyudi, A. Yani, and - Maspaeni, 2018, "Simulasi Pemilihan Program Studi Teknik Informatika Strata 1 pada Perguruan Tinggi Swasta di Pulau Lombok Dengan Menggunakan Pendekatan Metode Analytical Hierarchy Process," Explore, Vol. 8, No. 1, p. 19, doi: 10.35200/explore.v8i1.68. 